\title{
Peran Media Digital dalam Peningkatan Daya Saing Global Produk Kakao
}

\author{
Halifa Haqqi, Andika Drajat Murdani \\ Universitas Slamet Riyadi \\ halifa.haqqi@unisri.ac.id
}

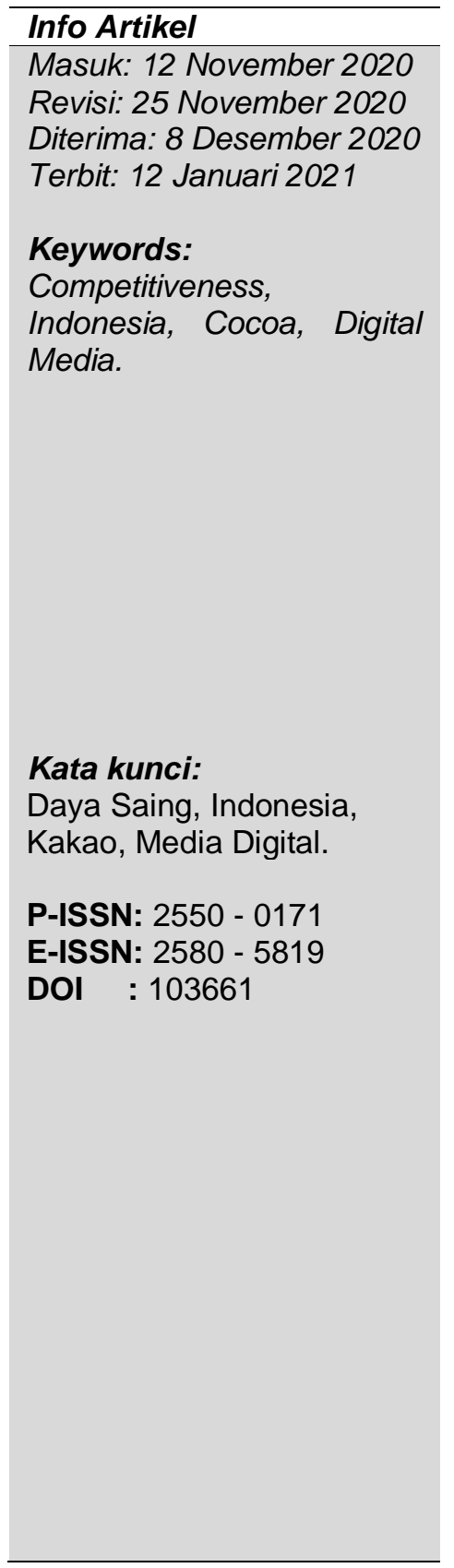

\begin{abstract}
Digital media opens opportunities to increase the competitiveness of various commodities at the global level, including cocoa products. Indonesia is the third largest cocoa producing country in the world. However, the competitiveness of Indonesia's was low. Synergies and the right policies were needed to encourage increased global competitiveness of cocoa products, especially by utilizing digital media. The purpose of this research was to find out what roles can be utilized by digital media in order to increase the global competitiveness of cocoa products. The research method used was qualitative descriptive. The results showed that the use of digital media can be a competitiveness analysis tool to optimize the comparative and competitive advantages of cocoa products, optimize marketing and market analysis in the upstream to downstream cocoa industry and optimize e-commerce to achieve market exposure, reduce operating costs, expand global reach, increase customer loyalty and supply management of the cocoa industry.
\end{abstract}

\footnotetext{
Abstrak

Media digital membuka peluang bagi upaya peningkatan daya saing berbagai komoditas di tingkat global, termasuk produk kakao. Indonesia adalah negara produsen kakao terbesar ketiga di dunia. Meski demikian, daya saing produk ekspor kakao Indonesia masih rendah. Untuk itu, dibutuhkan sinergi dan kebijakan yang tepat untuk mendorong peningkatan daya saing global produk kakao, terutama dengan memanfaatkan media digital. Tujuan penelitian ini adalah untuk mengetahui apa saja peran yang dapat dimanfaatkan dari media digital dalam rangka meningkatkan daya saing global produk kakao. Metode penelitian yang digunakan berupa kualitatif deskriptif dengan teknik pengumpulan data dengan wawancara. Hasil Penelitian menunjukkan bahwa pemanfaatan media digital dapat menjadi alat analisis daya saing untuk optimalisasi keunggulan komparatif dan kompetitif produk kakao, optimalisasi pemasaran dan analisis pasar pada industri kakao dari hulu ke hilir, serta optimalisasi ecommerce untuk mencapai market exposure, menurunkan operating cost, melebarkan global reach, meningkatkan customer loyalty dan supply management industry kakao.
} 


\section{PENDAHULUAN}

Dunia memasuki era revolusi industri 4.0 yang memiliki ciri khas tersendiri berupa Internet of Things (loT). Konsep loT menempatkan media digital pada posisi penting dalam interaksi antara manusia di seluruh dunia. Schwab (2016) menjelaskan Revolusi Industri 4.0 sebagai tahapan dalam pembangunan pengetahuan yang mengaburkan batas antara dunia fisikal, digital dan biologis. Kata kunci dari era ini adalah digitalisasi yang melingkupi berbagai aspek kehidupan manusia, termasuk pada digitalisasi jejaring; digitalisasi produk dan jasa; digitalisasi model bisnis dan akses pelanggan.

Masifnya perkembangan teknologi digital ini pun menjadi peluang tersendiri bagi mereka yang mampun menangkapnya. Hal ini juga berlaku bagi pengembangan daya saing produk komoditas pertanian seperti kakao. Pengembangan daya saing membutuhkan banyak daya upaya di tengah perekonomian global yang penuh dengan dinamika yang tidak menentu (Rosmadi, 2014:97). Para pelaku usaha harus mampu meningkatkan daya saing produk dan meningkatkan nilai kompetitif produknya. Persaingan usaha membutuhkan inovasi dan kreativitas serta pemanfaatan sarana yang tepat sebagai modal utama pengembangan daya saing produk yang dihasilkannya (Shofa, 2018:75).

Kemampuan adaptasi dari para pelaku usaha adalah hal penting, terutama terhadap perkembangan ilmu pengetahuan dan teknologi informasi yang semakin berkembang dewasa ini (Haerisma, 2018:92). Sayangnya, dalam perkembangannya, peluang pemanfaatan media digital untuk pengembangan ekonomi nasional selama ini lebih banyak dimanfaatkan negara maju dibandingkan negara-negara berkembang termasuk Indonesia (Ningsih, 2014:59). Padahal, perubahan dunia digital yang pesat, serta ketersediaan sumber informasi dalam jaringan komputer dan internet telah menghasilan perubahan dalam skema pemasaran tradisional dan sekaligus mampu mempengaruhi persepsi konsumen (Sweeney, 2005).

Padahal, komoditas kakao termasuk komoditas penting dan potensial bagi Indonesia jika bisa dikembangkan secara maksimal. Diharapkan para pelaku industri kakao, disertai dukungan dari para pembuat kebijakan mampu melakukan usahausaha peningkatan produksi dan kualitas produk kakao yang dihasilkan. Ketika hal ini dapat dilakukan, pertumbuhan perekonomian nasional dapat meningkat, beriringan dengan peningkatan pendapatan masyarakat, khususnya bagi para petani kakao serta pelaku industri kakao (Layli, 2012).

Potensi kakao telah banyak dibuktikan dari kemampuan komoditas kakao dalam menyumbangkan devisa kepada negara. Kontribusi devisa yang dihasilkan adalah yang terbesar ketiga pada subsektor perkebunan setelah karet dan kelapa sawit. Nilai ini menggambarkan adanya peran besar kakao dalam perekonomian nasional. Diperkirakan, 1,84 juta keluarga mengadalkan pendapatannya dari komoditas kakao, serta sekitar 1 juta keluarga lainnya mengandalkan pendapatannya dari industri hilir kakao (Rafiastuti, 2017).

Urgensi penelitian ini melihat bahwa nilai kontribusi komoditas kakao terhadap perekonomian nasional Indonesia tentu bisa dioptimalkan lagi ketika tingkat produktivitas kakao Indonesia bisa ditingkatkan. Ini sehubungan dengan rendahnya tingkat produktivitas kakao yang rata-rata hanya menghasilkan $534 \mathrm{~kg} / \mathrm{ha} / \mathrm{tahun}$, ketika potensinya mencapai lebih dari 2 ton/hektar/tahun. Belum lagi, kualitas biji kakao yang dianggap masih belum maksimal, serta nilai ekspor yang mayoritas masih 
berupa produk setengah jadi dengan daya saing rendah (Kementerian Pertanian, 2016).

Berangkat dari permasalahan ini, penelitian ini berupaya untuk mengangkat pertanyaan penelitian berupa "Bagaimana Peran Media Digital dalam Peningkatan Daya Saing Global Produk Kakao?". Dengan demikian, dapat dipetakan strategi maupun langkah kebijakan yang tepat guna mendorong optimalisasi daya saing global produk kakao, terutama dengan memanfaatkan media digital.

\section{METODE PENELITIAN}

Jenis penelitian yang digunakan adalah deskriptif kualitatif. Penelitian ini berupaya mendeskripsikan fenomena-fenomena sosial dan mengidentifikasi fenomena dalam masyarakat tersebut melalui observasi dan penelitian lapangan. Penelitian dilakukan melalui literature review dengan melihat pada rujukan data pustaka yang ditemukan dari berbagai sumber primer maupun sekunder. Selanjutnya, analisis dilakukan melalui pendekatan kualitatif deskriptif. Hasil akhir penelitian disajikan dalam bentuk naratif deskriptif yang bersifat menyeluruh disertai interpretasi terhadap seluruh aspek-aspek guna menjawab pertanyaan penelitian yang telah dirumuskan, yakni terkait peran media digital dalam peningkatan daya saing global produk kakao Indonesia.

\section{PEMBAHASAN}

\section{Daya Saing Global}

Perkembangan ekonomi internasional menciptakan hubungan yang menimbulkan saling ketergantungan (interdependence) antar negara-negara di dunia. Integrasi ekonomi ini menjadikan kesejahteraan suatu masyarakat sangat bergantung dari interaksinya dengan perekonomian global, serta kemampuannya dalam berdaya saing di pasar global. Sekalipun suatu komoditas ekonomi tidak melitas keluar negara, tapi ada kemungkinan ia terdampak oleh komoditas serupa yang masuk dari negara lain. Inilah yang membuat integrasi ekonomi jadi hal yang tidak terhindarkan.

Untuk itu, siapa pun pelaku ekonomi, dianggap perlu untuk mampu meningkatkan daya saingnya, agar bersiap untuk menghadapi persaingan global, baik untuk keluar negeri, maupun dalam menghadapi produk luar negeri yang masuk. Suatu negara, perlu untuk melindungi Economic interest atau kepentingan ekonomi yang berupa tambahan nilai secara ekonomi dalam interaksi perdagangan internasional. Hubungan ekonomi seharusnya dapat ditata untuk memenuhi economic interest negara ini (Shandri, $2017: 4-5)$.

Bagi Indonesia, komoditas kakao merupakan salah satu komoditas penting sebagai economic interest negara. Dinyatakan oleh Kementerian Pertanian, bahwa komoditas kakao memiliki potensi besar bagi peningkatan ekonomi nasional. Bahkan, kakao juga menjadi komoditas andalan ekspor nasional, selain kelapa sawit dan karet (Kementan, 2020). Dalam rangka menegaskan pentingnya komoditas kakao bagi Indonesia, Kementerian Pertanian terus berupaya untuk menekan hambatan ekspor produk kakao, terutama produk kakao olahan Indonesia. Salah satunya adalah menuju pasar Uni Eropa, yang dianggap menggairahkan. Telah ada dukungan diplomasi Indonesia - EU Comprehensive Economic Partnership Agreement (IEU CEPA) yang merupakan bentuk kerjasama diplomasi dalam rangka mengurangi 
tarifikasi kakao di Eropa, sekaligus meningkatkan konsumsi kakao olahan Indonesia pada wilayah tersebut (Kementan, 2020).

Potensi kakao di pasar global sangat besar dan terus mengalami peningkatan. World Cocoa Foundation menyatakan bahwa peningkatan tahunan permintaan kakao global mencapai tiga persen per tahun, selama seratus tahun terakhir. Diperkirakan, permintaan kakao dunia akan terus meningkat dengan tingkat yang sama di tahuntahun mendatang. Euromonitor juga turur menegaskan potensi peningkatan permintaan kakao dunia. Peningkatan permintaan coklat salah satunya karena alasan kesehatan dan rasa yang terutama terjadi di pasar Eropa Barat dan Amerika Utara (Euromonitor, 2016).

Konsep Daya Saing adalah kriteria dalam penentuan keberhasilan dan pencapaian tujuan yang lebih baik dari suatu negara dengan orientasi pada usaha peningkatan pendapatan dan pertumbuhan ekonomi. Dalam suatu komoditas ekonomi, daya saing berperan dalam menentukan posisi komoditi tersebut di pasar. Adapun indikator daya saing komoditi tersebut adalah bagaimana keluasan pangsa pasar. Ketika pangsa pasar komoditi tertentu mengalami peningkatan, artinya daya saing komoditi tersebut ikut meningkat (Martin et. al, 1991).

Sebagai salah satu produsen dan pengekspor kakao terbesar di dunia, tingginya minat pasar produk kakao menempatkan Indonesia pada posisi menguntungkan. Indonesia sendiri dianggap memiliki keunggulan kompetitif dalam komoditas kakao. Adapun keunggulan keunggulan kompetitif utama Indonesia terletak pada kemampuan untuk memasok biji kakao dengan harga murah murah dan dalam jumlah besar. Namun, sayangnya, kelemahan komoditas kakao dari Indonesia adalah kualitasnya yang rendah (Indonesia Investment, 2020).

Usaha untuk meningkatkan daya saing ini dapat dilakukan melalui analisis daya saing yang secara umum dilakukan melalui pendekatan pangsa pasar dan pertumbuhan pasar. Daya saing yang baik dapat dilihat ketika komoditi berhasil memiliki keunggulan komparatif dan keunggulan kompetitif (Martin et. al, 1991). Namun, yang perlu menjadi perhatian adalah Indonesia menghadapi kesulitan dalam meningkatkan peran penting kakao dalam pembangunan ekonomi Indonesia. Ini karena sekitar 90 persen produksi kakao Indonesia dihasilkan oleh petani kecil. Pada tahun 2017, dari total 1.724.366 Ha lahan kakao yang di Indonesia, sejumlah 1.678.205 adalah lahan yang dimiliki dan dikelola oleh pertanian rakyat atau para petani kecil (BPS, 2018).

Permasalahan terjadi karena para petani kecil ini tidak memiliki akses informasi serta kemampuan finansial untuk mengoptimalkan kapasitas produksi. Alhasill, kondisi ini mengakibatkan penurunan produksi karena pohon yang menua, penyakit, banjir, dan sebagainya (indonesia investment, 2020). Minimnya pemahaman para petani terhadap analisis daya saing produk kakao ini perlu untuk diatasi. Salah satu media potensial untuk mengatasinya adalah dengan media digital. Media digital dapat menjadi sarana penyebaran informasi yang lebih luas, serta mendukung upaya penyuluhan bagi para petani kakao. Apalagi, selama ini kinerja penyuluh pertanian kakao dianggap kurang optimal (KPPOD, 2016: 41).

Dengan memanfaatkan media digital sebagai alat analisis daya saing, optimalisasi keunggulan komparatif dan kompetitif produk kakao bisa diperoleh. Setidaknya, para petani kakao akan memiliki kesempatan untuk akses informasi dalam hal pengolahan lahan kakaonya, sehingga memiliki kualitas yang lebih baik. 
Terlebih, petani memiliki kesempatan untuk berinteraksi dengan penyuluh pertanian, serta dalam mengakses serta memahami pangsa pasar produk kakao.

\section{Nilai Ekonomi Media Digital}

Media digital dapat menjadi salah satu sarana dalam mendukung kegiatan ekonomi. Para ahli berpendapat bahwa media digital dapat menjadi pusat untuk product knowledge bagi konsumen. Kini, para konsumen memiliki kesempatan untuk meraih lebih banyak informasi terkait suatu produk atau jasa dengan memanfaatkan media digital. Hal ini juga menjadi peluang bagi pelaku usaha untuk menciptakan product knowlodge terhadap para konsumen sasaran (Singh, Veron, Jackson, \& Cullinane, 2008:283; Mangold \& Faulds, 2009; Kaplan \& Haenheim-A, 2010:60; Kaplan \& Haenhein-B, 2012:102).

Analisis ini mendukung pentingnya akses informasi dan media digital bagi para pelaku industri kakao di berbagai sektor. Para petani sebagai pihak yang mendominasi lahan kakao di Indonesia, juga penting untuk memiliki product knowledge, dengan menyesuaikan pada minat pasar. Selain itu, media digital sekaligus dapat menjadi media promosi kakao Indonesia di pasar global. Melalui media digital, Indonesia dapat mewujudkan total diplomacy guna mendukung promosi produk kakao Indonesia, demi menumbuhkan product knowledge bagi para konsumen global, terhadap produk kakao asal Indonesia.

Perlu dipahami bahwa persaingan usaha dalam berbagai komoditas menuntut setiap pelaku usaha untuk memenuhi kebutuhan konsumen. Pelaku usaha juga harus mampu menciptakan produk dengan keunggulan atau daya saing yang mumpuni serta menciptakan produk yang berbeda dari pesaing. Dengan semakin majunya perkembangan teknologi informasi, masyarakat mulai mengalami pola interaksi kegiatan ekonomi yang berbeda. Tercipta suatu interaksi yang serba cepat dan modern, yang berpengaruh pada perilaku informasi serta perilaku ekonomi (Maulana, Susilo, \& Riyadi, 2015:2).

Dari sinilah, peran serta stakeholders maupun para pelaku industri kakao lain dibutuhkan. Sinergi dalam memanfaatkan media digital diperlukan agar tercipta interaksi dalam kegiatan industri kakao dari hulu ke hilir, hingga sampai ke konsumen. Kondisi ini sekaligus menuntut para pelaku usaha untuk memiliki pemahaman yang cukup terkait media digital dan pemanfaatannya dalam dunia usaha. Media digital bagi pelaku usaha dapat dimanfaatkan untuk membangun product knowledge serta untuk interaksi dengan konsumen. Media digital juga dapat menjadi jalan untuk melakukan pemasaran hasil produksi menuju pangsa pasar sasasran (Gita, Putri, \& Sukarsa, 2013:144).

Selain itu, pemanfaatan media digital ini juga dapat menjadi komponen penting dalam strategi pemasaran dalam kegiatan ekonomi dan transaksi bisnis pada industri kakao. Dari sini, bisa ditekankan pentingnya upaya optimalisasi pemasaran dan analisis pasar melalui media digital untuk industri kakao, secara menyeluruh, terutama dari industri hilir kakao. Industri hilir, berarti adalah dengan menciptakan interaksi khusus dengan para konsumen kakao, sehingga lebih dekat dan mengenal keunggulan produk kakao Indonesia. 


\section{E-Commerce}

E-commerce merupakan singkatan electronic commerce, yang berarti interaksi antara sistem komunikasi, menejemen data dan keamanannya, yang menghasilkan adanya pertukaran informasi dalam relasi perdagangan barang atau jasa, dengan tujuan komersial E-commerce menjadi sarana utama perdagangan yang dilakukan secara elektronik dnegan komponen utama berupa sistem komunikasi, sistem menejemen dan keamanan (Nanehkaran, 2013 : 190).

Pengertian e-commerce lainnya diungkapkan oleh Lindsay P., (2002) dalam Khan 2016 sebagai suatu proses membeli dan menjual barang dan jasa melalui internet. Internet menjadi sarana untuk membeli dan menjual, sekaligus untuk mendapatkan informasi, membandingkan harga serta penawaran barang tertentu, sebagai bahan pertimbangan dalam melakukan transaksi lanjutan (Khan, 2016 : 19). Keberadaan internet dalam skema e commerce inilah yang dapat dimanfaatkan oleh para pelaku industri kakao serta para stakeholders dalam mengupayakan peningkatan daya saing global produk kakao.

Dalam hubungan transaksional, e-commerce dapat dimanfaatkan oleh konsumen dan pelaku bisnis. Para pelaku industri kakao Indonesia, dapat mengamati bagaimana hubungan transaksional yang berlangsung dalam skema bisnis kakao secara global. Adapun pemanfaatan e-commerce dalam aktivitas bisnis ini, dapat memberikan dampak positif, seperti :

- meningkatkan market exposure (pangsa pasar)

- menurunkan operating cost (biaya operasional)

- melebarkan global reach (jangkauan global)

- meningkatkan customer loyalty (kesetiaan pelanggan)

- menigkatkan supply management (managemen penyediaan barang)

Industri kakao pun dapat memperoleh kelima manfaat tersebut, dengan memanfaatkan media digital secara optimal. Sejalan dengan hasil penelitian yang disampaikan oleh Istiqomah dan Syarifatul (2015) terkait Perilaku Ekonomi Kakao Indonesia, disebutkan pentingnya peningkatan pengawasan dalam kebijakan yang berkaitan dengan penerapan teknologi. Skema ini misalnya dengan mengoptimalkan Grateks (Gerakan Teknologi) dan Gernas (Gerakan Nasional) kakao. Dengan optimalisasi ini, potensi dihasilkannya kakao dengan kuantitas yang lebih banyak dan kualitas yang lebih baik akan semakin meningkat.

Merujuk pada penelitian yang dilakukan Kindangen, Hartoyo dan Baga (2015), disebutkan bahwa teknologi dan harga domestik memiliki pengaruh positif terhadap produktivitas biji kakao dan juga terhadap upah buruh. Hal ini menunjukkan bahwa penerapan teknologi, termasuk dalam media digital yang tepat dapat memberikan kontribusi dalam optimalisasi daya saing global dari industri kakao. Oleh karena itu, pemerintah perlu menyiapkan skema kebijakan teknologi yang mampu mengakomodasi kepentingan guna menunjang produksi. Hal ini bisa dilakukan dengan mempertemukan aspek promosi, demi mendatangkan investasi baru, sehingga pada akhirnya dapat tercipta hubungan positif antara produksi dan teknologi media digital. Dari sini, muara dari implementasi ini diharapkan terjadi optimalisasi $e$ commerce untuk mencapai market exposure, menurunkan operating cost, melebarkan global reach, meningkatkan customer loyalty dan supply management industry kakao. 


\section{KESIMPULAN}

Kajian penelitian ini berusaha untuk mengetahui peran media digital dalam usaha-usaha peningkatan daya saing global produk kakao. Kondisi ini dapat dijabarkan dengan melihat pada potensi daya saing, serta relasinya dengan pemanfaatan media digital dan e-commerce. Diperoleh kesimpulan bahwa peran media digital, merujuk pada tiga peran utama, yakni: (1) media digital sebagai alat analisis daya saing untuk optimalisasi keunggulan komparatif dan kompetitif produk kakao; (2) Optimalisasi pemasaran dan analisis pasar melalui media digital untuk industri kakao dari hulu ke hilir; (3) pptimalisasi e-commerce untuk mencapai market exposure, menurunkan operating cost, melebarkan global reach, meningkatkan customer loyalty dan supply management industry kakao.

\section{DAFTAR PUSTAKA}

Euromonitor International. 2016. Global trends and developments in Cocoa ingredients (world). Retrieved from https://www.euromonitor.com/global-trendsand-developments-in-cocoa-ingredients-world/report

Gita, S. D., Putri, P., \& Sukarsa, I. 2013. Pengaruh Harga Canang dan Pendapatan Konsumen Terhadap Permintaan Canang di Desa Sanur. Jurnal Ekonomi Pembangunan, 2(3), 142-151.

Indonesia investment. 2020. Cocoa in Indonesia. Diakses dari https://www.indonesiainvestments.com/id/bisnis/komoditas/kakao/item241?

Istiqomah, Syarifatul. 2015. Perilaku Ekonomi Kakao Indonesia. Magister thesis, Universitas Brawijaya.

Kaplan, \& Haenheim, M. 2010. Users of the World, Unite! The Challenges and Opportunities of Social Media. The Business Horizons, 53, 59-68.

Kementan. 2020. Menggenjot Ekspor Kakao Indonesia di Uni Eropa. Jakarta: Kementerian Pertanian Republik Indonesia.

Khan, Abdul Gaffar. 2016. Electronic Commerce: A Study on Benefits and Challenges in an Emerging Economy. USA : Global Journal of Management and Business Research: B Economics and Commerce, Volume 16 Issue 1 Version 1.0

Kindangen, Henoch, Sri Hartoyo dan Lukman M Baga. 2017. Perkembangan Produktivitas, Luas Lahan, Harga Domestik, Permintaan Dan Ekspor Biji Kakao Indonesia Periode 1990-2013. Jurnal Manajemen \& Agribisnis, Vol. 14 No. 2, Juli 2017.

Mangold, W., \& Faulds, D. 2009. Social Media: The New Hybrid Element of the Promotion Mix. Business Horizons, 357-363.

Maulana, S. M., Susilo, H., \& Riyadi. 2015. Implementasi E-Commerce Sebagai Media Penjualan Online (Studi Kasus Pada Toko Pasbrik Kota Malang). Jurnal Administrasi Bisnis (JAB), 29(1), 1-9.

Nanehkaran, Yaser Ahangari. 2013. An Introduction to Electronic Commerce. Turkey : International Journal of Scientific \& Technology Research Volume 2, Issue 4, April 2013. ISSN 2277-8616. 
Ningsih, C. 2014. Sinergitas Industri kreatif Berbasis Pariwisata Dengan Strategi Pembangunan Industri Nasional Menuju Globalisasi. Jurnal Manajemen Resort \& Leisure, 11(1), 59-64

Pohan, Syafruddin, Hazairin Pohan dan Indah Nuria Savitri. 2016. Digital DiplomacyMaximizing Social Media in Indonesia's Economic and Cultural Diplomacy. Journal of Advances in Social Science, Education and Humanities Research (ASSEHR), volume 81

Romdonny, Jefry, Maskarto Lucky dan Nara Rosmadi. 2018. Peran Media Sosial Dalam Mendukung Pemasaran Produk Organisasi Bisnis. Jurnal IKRAITH EKONOMIKA Vol 1 No 2 Bulan November 2018

Rosmadi, M. L. 2018. Faktor Turnover Intention Karyawan Pada organisasi Bisnis. Jurnal Bisnis dan Ekonomi Islam (BISEI), 3(1), 34-40

Satya, Venti Eka. 2018. Strategi Indonesia Menghadapi Industri 4.0. Pusat Penelitian Bidang Ekonomi Dan Kebijakan Publik Badan Keahlian DPR RI. Vol. X, No. 09///Puslit/Mei/2018

Shofa, I., \& Nugroho, D. 2018. Pertumbuhan dan Strategi Pengembangan Ekonomi Kreatif Kota Malang. Jurnal Pangripta, 1(1), 75- 85..

Slamet, Rachmat dkk. 2016. Strategi Pengembangan UKM Digital Dalam Menghadapi Era Pasar Bebas. Jurnal Manajemen Indonesia Vol.16 - No.2 April 2016

Sweeney, S. 2005. 101 Ways to Promote Your Website (5 ed.). Canada: Maximum Press. 